\title{
МОТОЧАС КАК ФАКТОР ОБЕСПЕЧЕНИЯ НАДЕЖНОЙ ЭКСПЛУАТАЦИИ СУДОВЫХ ЭНЕРГЕТИЧЕСКИХ УСТАНОВОК
}

Доцент, канд. техн. наук Литвиненко В. П., доцент, канд. техн. наук Берестовой И. О., Ковальчук Н. А., Спиридонов В. В., Ландиков Ю. В.

Украина, г. Мариуполь, Азовский морской институт НУ «ОМА».

DOI: https://doi.org/10.31435/rsglobal_wos/31102019/6734

\section{ARTICLE INFO}

Received: 20 August 2019

Accepted: 14 October 2019

Published: 31 October 2019

\section{KEYWORDS}

reliability of ship power plants; motohour; service program and repair; modes of loading; rate of wear of details; probability of faultless work; work on a refuse; controlling.

\begin{abstract}
The questions of increase of reliability of exploitation of main ship diesel and power plants are considered due to an account and introduction of facilities of automation of calculation of workhours on a refuse. Possibility of calculation of running hours of ship power plants is marked by the use of data that is fixed during exploitation of modern courts of mercantile fleet. Formal dependence over of calculation of running hours, taking into account the modes of loading on a main diesel, is brought.
\end{abstract}

Citation: Литвиненко В. П., Берестовой И. О., Ковальчук Н. А., Спиридонов В. В., Ландиков Ю. В. (2019) Motochas kak Faktor Obespecheniya Nadezhnoj Ekspluatacii Sudovyh Eenergeticheskih Ustanovok. International Academy Journal Web of Scholar. 10(40), doi: 10.31435/rsglobal_wos/31102019/6734

Copyright: ( 2019 Литвиненко В. П., Берестовой И. О., Ковальчук Н. А., Спиридонов В. В., Ландиков Ю. В. This is an open-access article distributed under the terms of the Creative Commons Attribution License (CC BY). The use, distribution or reproduction in other forums is permitted, provided the original author(s) or licensor are credited and that the original publication in this journal is cited, in accordance with accepted academic practice. No use, distribution or reproduction is permitted which does not comply with these terms.

Постановка задачи. В современных условиях эксплуатации торгового флота вопросы обеспечения надежной эксплуатации судовых энергетических установок (СЭУ) достигаются через посредство использования планово-предупредительной системы технического обслуживания. Причем, в качестве критерия, определяющего периодичность обслуживания, используется «наработка» на отказ, выраженная в часах работы главного дизеля (ГД). Однако, как это следует из результатов практических наблюдений, при таком подходе не принимаются во внимание особенности режимов нагрузки на основные компоненты ГД и СЭУ, которые проявляются во время маневров, изменения винтовой характеристики (загрузки судна, погодных условий, обрастания гребного винта и корпуса судна), и сопряжены с их интенсивным износом. Не учитываются также конструктивно-технологическая специфика судна, особенности маршрута его следования, сезонность выполняемых рейсов и многих других факторов.

Как показывает практика, для различных типов судов изготовитель ГД указывает усредненное время наработки компонентов на отказ (с момента пуска двигателя и до полной остановки, по штатному счетчику оборотов), не принимая во внимание изменяющиеся режимы его работы, характерные для эксплуатации судна.

В качестве примера изменяющейся нагрузки и, как следствие темпа износа, можно отметить ГД модели $\mathrm{B} \& \mathrm{~W} 6 \mathrm{~S} 60 \mathrm{MC}$, устанавливаемые на балкерах или танкеры. Эти суда в основном эксплуатируются на длинных переходах, продолжительность которых составляет 20 - 30 дней и ГД работает на маневренных «тяжелых» режимах от двух до четырех раз при заходах и выходах из порта для выполнения грузовых операций. Эта же модель ГД, установленная на контейнеровозе, Ro-Ro или Ferry Ship используются на маневренных «тяжелых» режимах значительно интенсивней в связи с портовыми заходами $2 \div 3$ раза в течение $5 \div 7$ дней и чаще. 
Изменяющиеся режимы нагрузок на ГД в значительной мере влияют на темпы износа деталей цилиндропоршневой группы и кривошипно-шатунного механизма. В особенности это вызвано тяжелыми маневровыми режимами эксплуатации, которые вызваны необходимостью выполнения реверсов, связанных с использованием контрвоздуха и частыми пусками, резкими изменениями оборотов при нагрузках, разгонах дизеля от самого малого хода (Dead Slow) до полного маневрового хода (Full maneuvering mode). При таких режимах работы ГД износ деталей цилиндропоршневой группы предположительно возрастает в шесть, восемь раз, по отношению к режимам номинальных нагрузок. Это обстоятельство, однако, не принимается во внимание при составлении графиков выполнения планово-предупредительных работ и не отображается на штатных приборах регистрации продолжительности работы ГД.

Не учитывается отмеченное условие также программой технического обслуживания PMS (Planning Maintenance System) «AMOS D» или «Ship Shure» которая адаптирована к конкретному типу двигателя и согласно требованиям Международной конвенцией SOLAS, одобрена Классом Регистра и Администрацией флага и должна устанавливаться на всех судах вместимостью более 500 регистровых тонн.

Цель исследования данной работы - разработка теоретических и инженерных решений, обеспечивающих учет наработки на отказ в зависимости от режимов нагрузки главного дизеля и СЭУ, с целью установления оптимальных периодов обслуживания.

\section{Изложение основного материала.}

В сложившейся практике эксплуатации судов обеспечение надежности работы СЭУ достигается благодаря использованию программ обслуживания, которые разработаны фирмами, занятыми их производством. Эти программы являются обязательными для исполнения судовладельцами и служат нормативным документом для надзора над техническим состоянием со стороны классификационных обществ. В целом, программы обслуживания согласуются с требованиями действующих Правил технической эксплуатации судовых технических средств и конструкций, используемых в качестве нормативного документа для судов, эксплуатируемых под флагом Украины, и зарегистрированных инспекцией государственного надзора морского торгового флота, [1,2].

Структурно такие программы предполагают выполнение операций обслуживания по расписанию, составленному в виде план-графика и выполнение ремонтных работ по необходимости. Причем необходимость в ремонтных работах может возникнуть внепланово, в связи с наработкой на отказ, раньше установленного графиком обслуживания срока. Как следует из результатов практического наблюдения над ГД, до $80 \%$ работ по обслуживанию выполняются с отклонениями от установленной периодичности. Так что, принимая во внимание это обстоятельство и априори полагая, что причиной таких отклонений является дисциплина соблюдения планов обслуживания, вызванная несоблюдением предусмотренных сроков выполнения работ, в современных условиях находят широкое применение электронные системы контроля. Примерами таких программ является программное обеспечение, разработанное фирмами AMOS и Xantic, которое включает в себя блоки управления и контроля. Однако такие решения, не смотря на их очевидную полезность в управлении процессом технической эксплуатации судна, не привели к снижению отмечаемых неплановых отказов в работе дизеля.

Как показали результаты обследований, выполненных в рамках настоящей работы, отмечаемые несоответствия обусловлены действующими нормами периодичности обслуживания дизеля, которые жестко регламентированы и приведены в инструкциях по эксплуатации.

Программами предусматривается обязательное выполнение работ, связанных с переборкой дизеля и СЭУ, которые трудоемки и оказывают влияние на показатели надежности при дальнейшей эксплуатации. Эта периодичность, как правило, принимаются во внимание классификационными обществами (Регистром) в качестве предельных сроков наработки узлов и деталей дизеля, выполнение которых оказывается к исполнению обязательно, вне зависимости от их состояния, [3-5]. В таких программах используется понятие наработки на отказ, которое трактуется в виде часов фактической работы дизеля, без учета специфики эксплуатации судна и района плавания, уровня нагрузки на дизель, типа судна и многих других условий. Таким образом, ставится в однозначное соответствие понятие наработки на отказ с фактическим временем работы дизеля, что представляется не вполне корректным. 
Реализация этого подхода приводит к существенным искажениям оценки технического состояния узлов и деталей дизеля и, как следствие, назначением работ по обслуживанию и ремонту в периоды, когда моторесурс дизеля оказывается еще не реализованным либо уже исчерпанным. С позиций обеспечения безопасности плавания судов, назначение периодов обслуживания и контроля судовых энергетических установок (СЭУ) по времени представляется не вполне эффективным, а сама система планово-предупредительного обслуживания и контроля требует определенных корректировок и совершенствований.

Такое обобщение корреспондируется с тенденциями развития принципа организации обслуживания и контроля технического состояния СЭУ по состоянию, за счет внедрения в конструкцию судов все более совершенных средств автоматизации средств диагностики. Однако до настоящего времени использование этого метода еще не получило должного применения, что, повидимому, характерно ограниченностью охвата средствами диагностики конструктивных элементов судна. По меньшей мере, контролирующие техническое состояние органы в виде инспекции регистра и других классификационных обществ, диагностические признаки средств автоматизации принимаются как некоторый косвенный показатель. Большею частью при проверках технического состояния судов, инспекторы прибегают к прямой диагностике технического состояния элементов конструкции за счет вскрытия и демонтажа узлов при условии соблюдения периодичности, предусмотренной заводом-строителем дизеля или других технических средств, [6].

Программы обслуживания, предложенные заводом-строителем дизеля, используются также техническими службами судовладельцев для составления планов-графиков обслуживания флота и материально-технического обеспечения судов, находящихся в эксплуатации. В этом отношении они оказываются одним из основополагающих документов, который используется при планировании затрат компании судовладельца. Очевидно, что в практике эксплуатации судов реализация программ обслуживания, существенно влияет и на экономические показатели компании, все здесь зависит от эксплуатационных условий работы, типа судна, района плавания и многих других факторов.

Таким образом, на основании выполненного анализа состояния рассматриваемого вопроса, можно сделать вывод о том, что сложившаяся практика организации обслуживания и контроля СЭУ по периодичности, установленной заводом-строителем судна, не в полной мере соответствует реальным потребностям эксплуатации.

Основой таких несоответствий является на наш взгляд оценка длительности времени «наработки на отказ» - «Operating time between failures», которое положено в основу программ обслуживания и контроля технического состояния СЭУ и в первую очередь ГД со значениями, наблюдаемыми на практике, [7]. В общетеоретическом представлении наработка на отказ отображается в виде выражения:

$$
\mathrm{T}_{0}=\int_{0}^{t} P(t) d t,
$$

где $P(t)$ - вероятность безотказной работы в интервале времени $0<\mathrm{t}<T$.

В судовой практике наработка на отказ фиксируется в моточасах работы СЭУ, под которыми понимается период работы механизма, [8]. Здесь не принимается во внимание, что моточас является комплексным интервальным показателем, который используется в технике не только как временной параметр, но и как показатель нагрузки на механизмы.

В общетехническом понимании моточас как параметр, отображающий работоспособность техники, нашел широкое применение в различных отраслях современности, он определяется как вероятностная характеристика, учитывающая различные режимы работы механизма. В международной практике его обозначают Mean Time To Failure - среднее время до отказа, сокращенно МTTF. Использование параметра не является стандартизованным и по этой причине в сложившейся практике эксплуатации транспорта он рассматривается в различном смысловом содержании. По этой причине, заметим, что относительно рассматриваемой проблематики, моточас нами рассматривается как параметр измерения нагрузки на СЭУ, от которой зависит темп износа деталей ГД или СЭУ. Такое определение представляется наиболее согласующимся с принятыми подходами в теории надежности.

На современных судах регистрация наработки на отказ осуществляется использованием тахометрических комплексов. Они обеспечивают измерение частоты вращения, суммарных оборотов и времени работы, определяют направление вращения и сигнализируют о достижении 
заданной частоты вращения. Конструктивно реализация отмечаемой функции достигается за счет применения механических и электронных схем. В современных конструкциях СЭУ большею частью применяются электронные устройства, работа которых обеспечивается за счет электрических импульсов, образуемых при вращении вала и использования электромагнитов, а также благодаря установке соответствующих датчиков и счетчиков - суммирующего счетчика оборотов, счетчика продолжительности работы, счетчика количества изменения нагрузки, счетчика количества пусков двигателя. При этом счетчик, фиксирующий режимы нагрузки дизеля, работает по принципу записи длительного ходового режима и маневрирования (реверсов дизеля).

Современные конструкции судовых дизелей обустроены системами снятия часов наработки использованием отмеченного принципа, но адаптированы к компьютерным технологиям. В частности, на дизелях фирмы Бурмейстер и Вайн используются системы EGS 2200 - STD, которые устанавливаются на дизели серии МC - С и ME.

Отмеченные особенности в конструкции современных судовых СЭУ позволяют дифференцировать длительность их работы с учетом нагрузок и таким образом определить моточасы их работы, в трактовке этого параметра который отмечен нами. Для этого, безусловно, потребуется привнесение некоторой корректировки в расчетах наработки на отказ, а также принятия соответствующей нормативной базы, которая могла бы быть использована в компаниях и классификационных обществах.

Например, в основу расчета показателей безотказной работы судового дизеля и как следствие определения периода его технического обслуживания и осмотров, может быть положена информация, которая регистрируется в вахтенном журнале в виде отработанных часов. В таких журналах делаются следующие отметки: Running hors - моточасы, с их разделением по времени на предшествующие показатели на 12.00 - last non и последующие показатели на 12.00 - last sciences, а также сумму этих показаний - at noon.

Кроме этого, в журнале отмечается работа дизеля на соответствующих типичных режимах: в ходовом режиме - Full speed, в маневровом режиме - Reduced speed и в не рабочем состоянии - Stop.

Таким образом, у инженерной службы судна, как и технической службы судовладельца, всегда предоставляется возможность оценки состояния СЭУ и принятия, необходимых мер к устранению наблюдаемых неисправностей. Такое положение относится, в том числе и к контролю наработки СЭУ в период всего жизненного цикла.

Для наглядного отображения отмеченных систем контроля наработки на отказ и оценки технического состояния ГД, нами приведена принципиальная схема конструкции системы анализа работы дизеля - Diesel Performance Analyzer. Функционально эта система обеспечивает возможность фиксации наработки дизеля в часах работы, а также снятия значительного количества других значимых диагностических параметров. Принципиальная схема системы отображена на рис. 1.

Предположительно, знание отмеченных параметров, которые фиксируются на современных судах, обеспечит возможность расчета периодичности обслуживания по длительности времени работы ГД на соответствующих режимах нагрузки.

На начальном этапе исследования нами принимались во внимание работа ГД по следующим режимам работы: маневровый режим; номинальный и экстремальный. Так что суммарное количество моточасов работы ГД выразится следующим простым соотношением:

$$
\mathrm{MЧ}=\mathrm{MЧ}_{\mathrm{M}}+\mathrm{MЧ}_{\mathrm{H}}+\mathrm{MЧ}_{\ni}
$$

где, $\mathrm{MЧ}_{\mathrm{M}}$ - моточасы маневрового режима ГД; $\mathrm{MЧ}_{\mathrm{H}}$ - моточасы работы дизеля в пределах номинальной нагрузки, при нахождении судна на переходах; $\mathrm{MЧ}_{э}$ - моточасы работы дизеля в экстремальных условиях, когда нагрузка превышала номинальное число оборотов, равное $100 \%$.

Продолжительность $\mathrm{MЧ}_{\mathrm{M}}$ и МЧ который предусмотрен для номинальной нагрузки на дизель. Из условия, что на маневровом режиме темп износа будет составлять - $\xi_{\mathrm{m}}$, а при экстремальном режиме - $\xi_{\ni}$.

При этом, как отмечалось $\xi_{\mathrm{M}}>[\xi]$, также как и $\xi_{\ni}>[\xi]$. В приводимом нами примере под темпом износа понимается износ деталей цилиндропоршневой группы, выраженный в миллиграммах за один час работы, мг/час, как части конструкции дизеля в наибольшей степени подверженной износу. 


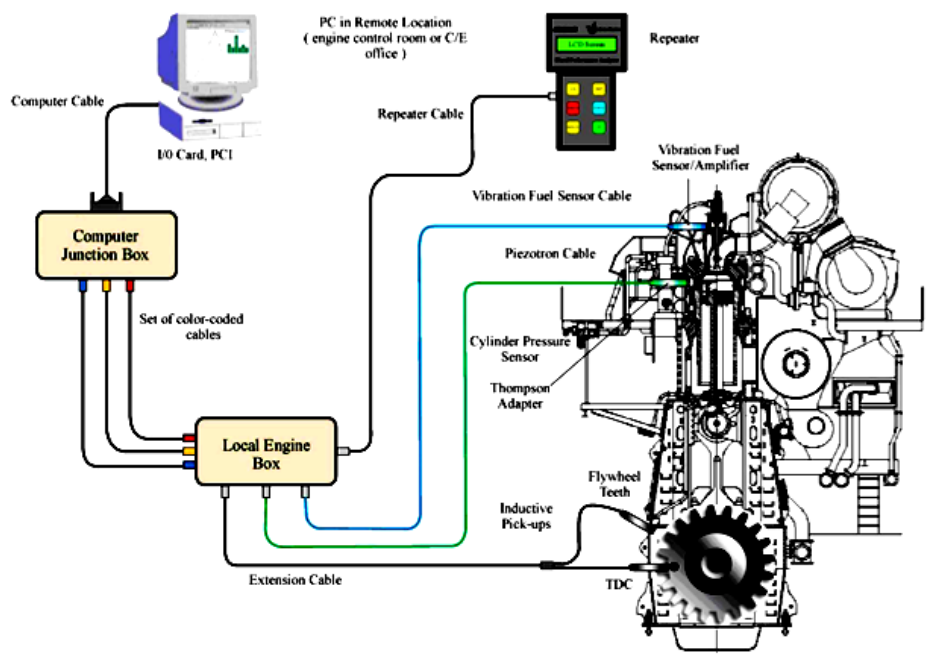

Рис. 1. Принципиальная схема системы анализа работы дизеля DPA - Diesel Performance Analyzer.

Таким образом, можно отметить, что моточасы работы дизеля на маневрах составят:

$$
\mathrm{MЧ}_{\mathrm{M}}=\frac{\xi_{\mathrm{M}}}{[\xi]} \cdot k \cdot t_{\mathrm{M}}
$$

где, $k$ - количество маневров за рассматриваемый период; $t_{\mathrm{m}}$ - длительность одного маневра.

Моточасы работы дизеля в экстремальных условиях составят:

$$
\mathrm{M \Psi}_{\ni}=\frac{\xi_{\mathrm{M}}}{[\xi]} \cdot \mathrm{T}_{\ni}
$$

где, $\mathrm{T}_{\ni}$ - продолжительность работы дизеля в экстремальных условиях.

Подставив выражение (3), (4) в (2) будем иметь:

$$
\mathrm{MЧ}=\frac{\xi_{\mathrm{M}}}{[\xi]} \cdot k \cdot t_{\mathrm{M}}+\mathrm{MЧ}_{\mathrm{H}}+\frac{\xi_{\mathrm{M}}}{[\xi]} \cdot \mathrm{T}_{\ni}
$$

Приведенная зависимость является ориентировочной, поскольку рассматриваемый вопрос требует необходимого статистического материала, обработка которого позволит выявить закономерности и эмпирические зависимости, позволяющие судить об особенностях наработки на отказ рассматриваемых элементов СЭУ. Однако, в целом, зависимость отображает существенность вероятных отклонений периодичности обслуживания СЭУ, которые сложились на практике.

Методически реализация отмечаемой нами методики может быть осуществлена использованием установленного на судне оборудования и программного обеспечения PMS такого как «AMOS D» или «Ship Shure». Причем для этого возможно использование действующей системы контроля над работой судна, принципиальная схема которого приведена на рис. 2.

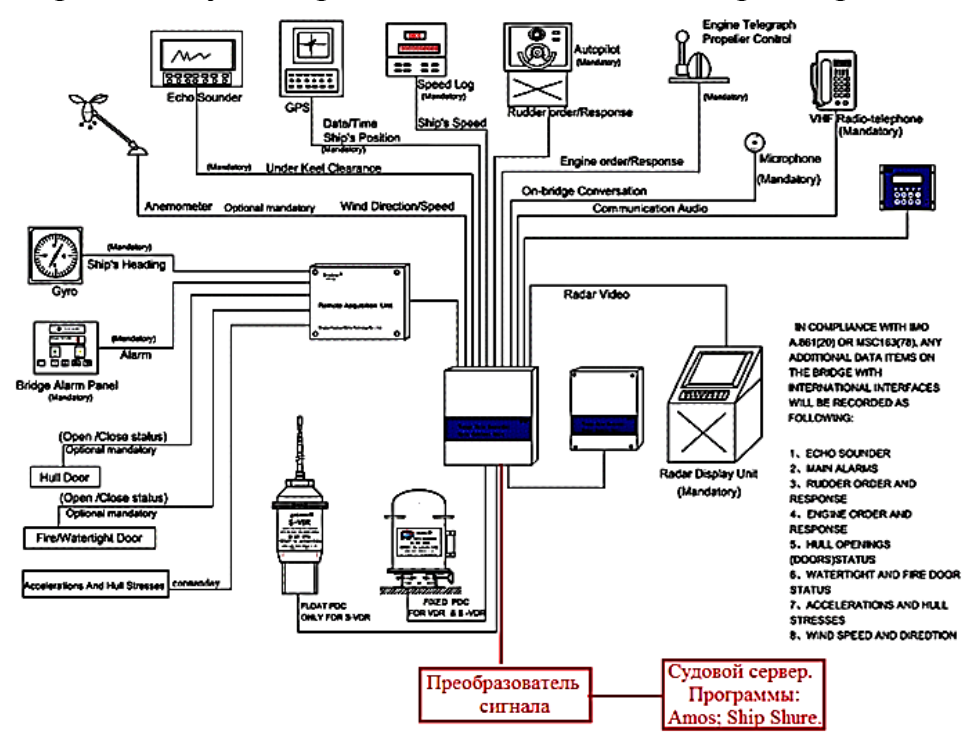

Рис. 2. Система контроля над работой судна. 
При соответствующей корректировке действующей системы имеется достаточно оснований полагать, что вопросы планирования планово-предупредительного обслуживания в наибольшей степени будут соответствовать реальным потребностям, что позволит повысить безопасность мореплавания и приведет к существенной эффективности для судовладельцев.

Безусловно, таким образом, представиться возможность повысить контроллинг эксплуатации судна в целом, под которым нами понимаются вопросы управления, планирования, учета, анализа и контроля над техническим состоянием СЭУ, которые направлены на достижение надежной и безопасной эксплуатации судна, [9].

Выводы.

1. В современных условиях наблюдается несоответствие периодичности выполнения работ по плановому обслуживанию и ремонту СЭУ с фактической потребностью в их выполнении, что приводит к снижению уровня надежности и безопасности эксплуатации судов торгового флота.

2. Установление периодичности выполнения плановых работ обслуживания и ремонта осуществляется по часам работы СЭУ, без учета типа судна, особенностей маршрута движения, климатических условий, маневровых операций и других эксплуатационных факторов, которые влияют на показатели надежности.

3. Предлагаемый метод определения периодичности наработки, на отказ, основываясь на фактически наблюденных нагрузках, выраженных в моточасах, позволяет минимизировать не соответствия между фактической потребностью в выполнении работ по облуживанию СЭУ и плановыми значениями.

4. Реализация предложенного метода установления периодичности может быть осуществлена использованием штатного оборудования, которое установлено на современных судах, при условии проведения дополнительных исследований и внесении соответствующих корректировок в программное обеспечение их работы.

\section{ЛИТЕРАТУРА}

1. Правила технической эксплуатации судовых технических средств и конструкций. РД 31.21 .30 - 97. - Санкт-Петербург: ЦНИИМФ, 1997. - 344c.

2. Комплексная система технического обслуживания и ремонта судов. Основное руководство. РД 31.20 .50 - 87. - М.: Мортехинформреклама, 1988. - 220c.

3. Руководство по техническому надзору за судами в эксплуатации. - Санкт-Петербург: Российский Морской Регистр Судоходства, 2000. - 423с.

4. Яхьятов Н.Я., Ханутсранов М.Д. Моделирование износа и определение срока службы втулок цилиндров судовых дизелей/ Н.Я. Яхьятов, М.Д. Ханутсранов. //Двигатели внутреннего сгорания. Х: ХПИ. - 2010. - №1. - С. $106-110$.

5. Правила технической эксплуатации судовых дизелей. - М: Русская панорама, 1999. - 168c.

6. Правила классификационных освидетельствований судов. Санкт-Петербург: Российский Морской Регистр Судоходства, 1998. - 141с.

7. Межгосударственный стандарт. Надежность в технике. Термины и определения: ГОСТ 27.002-2015. - [Введен в действие от 2015-03-01]. - М.: Стандартинформ, 2015

8. Военно-морской словарь/ под ред. Чернавин В.И. - М.: Воениздат, 1990. - 511с.

9. Контроллинг в бизнесе. Методические и практические основы построения контроллинга в организациях / А.М. Карминского, Н.И. Оленева, А.Г. Примака, С.Г. Фалько. - М.: Финансы и статистика, 2007. 